3. Apple Support. Taking an ECG with the ECG app on Apple watch series 4 or later. Available at: https://support.apple. com/en-us/HT208955. Accessed April 3, 2020.

4. De Gasperi RN, Duncan RC, Lowery MH, Chakko CS, Sequeira RF. Comparison of digitized ECGs simultaneously recorded with $\mathrm{CR}$ and $\mathrm{V}$ leads. $J$ Electrocardiol. 1995;28(4):287-95.

5. De Gasperi RN, McCulloh DH. CR Leads in cardiac emergencies. A preliminary study. Chest. 1991;99(4):904-10.

\section{Mountain Rescue During the COVID-19 Outbreak: Considerations and Practical Implications}

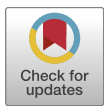

\section{To the Editor:}

The World Health Organization (WHO) was informed by the Chinese authorities in December 2019 of the presence of a viral outbreak probably originating from a fish and animal market in the city of Wuhan, the capital of central China's Hubei province. ${ }^{1}$ The responsible virus, a new $B$-Coronavirus RNA, was identified in early January 2020 and was named SARSCoV-2. ${ }^{2}$ The virus causes a flu-like illness that has been called COVID-19. The disease can manifest with mild symptoms or lead to severe pneumonia with hypoxemic respiratory failure, multiorgan failure, and death. ${ }^{3,4}$ The WHO declared a pandemic on March 11, 2020, due to the rapid spread of the new virus worldwide.

The diffusion of the COVID-19 pandemic forced governments in many countries to declare lockdowns to slow the spread of the virus and prevent the collapse of public health systems. For this reason, a temporary abolition of outdoor activities has been reported.

The reduction of quarantine restrictions, foreseen as a gradual return to regular activities, will likely lead to an increase in people practicing outdoor sports and could increase the number of accidents related to these activities. The COVID-19 pandemic has led to several issues during rescue operations in the wilderness environment due to concern about viral contagiousness during prolonged close interaction between rescuers and victims.

The National Alpine and Speleological Rescue Corps is a voluntary association in Italy that provides a complete range of rescue operation services in both the mountains and speleological environments. It also contributes to the prevention and surveillance of mountain sports and speleological activities in these same areas. As an operating structure of the national service belonging to the civil protection department, it gives assistance outside the mountain territory during disasters.

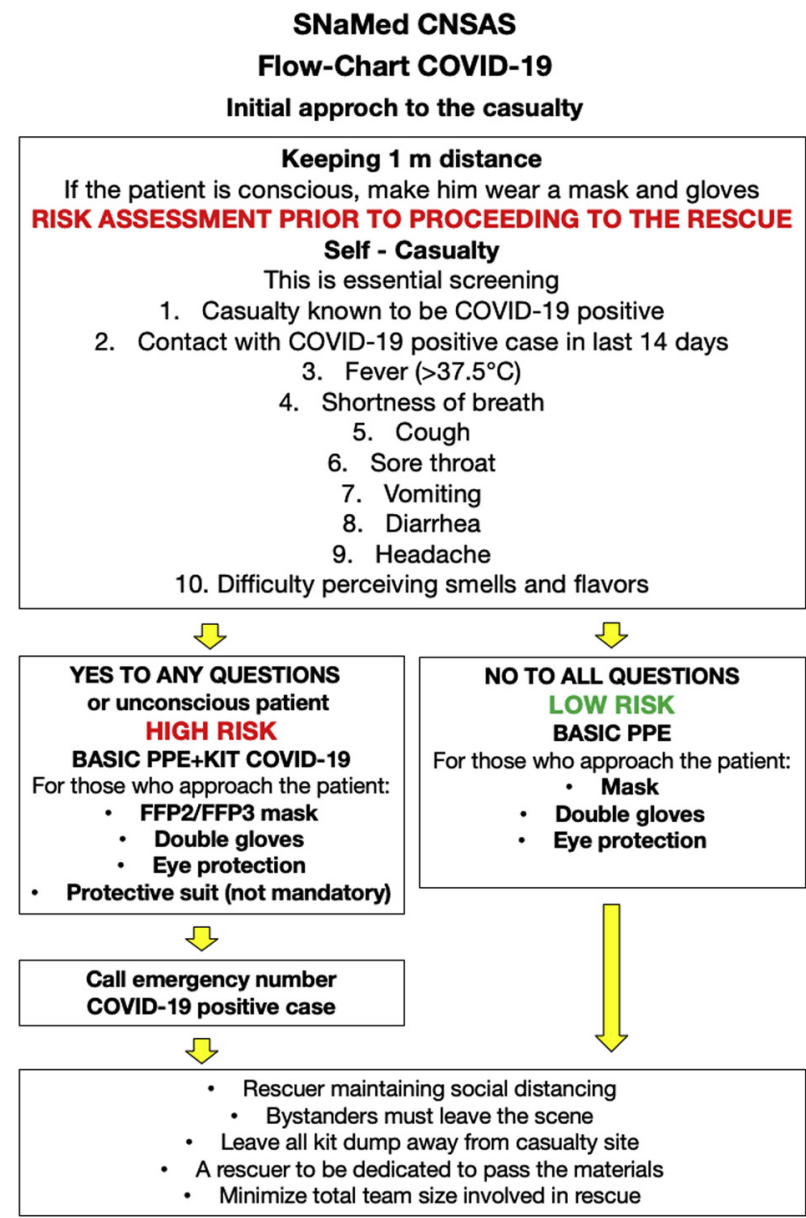

Figure 1. Algorithm showing initial approach to the victim.

SARS-CoV-2 mostly spreads from human to human via droplets, contact, and natural aerosols. Although the transmission route of COVID-19 is primarily through symptomatic patients, ${ }^{5}$ human-to-human transmission also appears to occur during the nonsymptomatic incubation period of the disease. The key considerations during rescues are protecting operators and patients from infection and disinfecting materials and vehicles used during outdoor operations. First, rescue operators should undergo health surveillance: reverse-transcriptase polymerase chain reaction to detect SARS-CoV-2 RNA in nose/throat swab sampling or immunological tests for IgM or IgG. Seroconversion for IgG and IgM can be helpful for the diagnosis of infection in individuals with negative reverse-transcriptase polymerase chain reaction results and for the identification of asymptomatic infections. ${ }^{6}$ In addition, each rescuer, before indicating availability to participate in rescue operations, should perform a self-check through a COVID-19 screening questionnaire (Fig. 1). In the case 


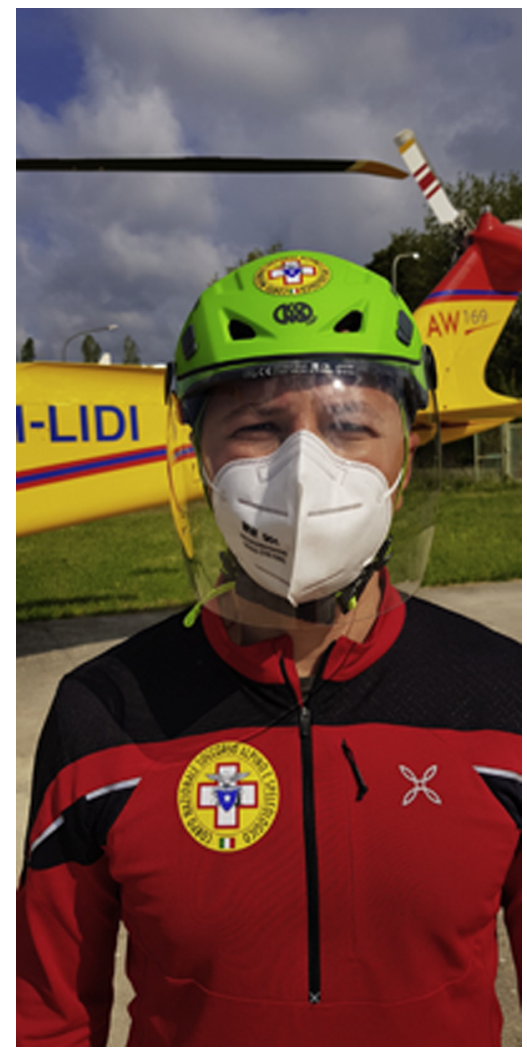

Figure 2. Rescue operator wearing long visor helmet and FFP2.

of even 1 positive response, participation in the rescue should be waived.

During the rescue operation, all operators should wear gloves, facial mask, and goggles during the approach to the vehicle. In the approach to a conscious victim by land, rescuers should give the patient a facial mask and gloves while maintaining a 1-m distance. When rescuers reach an injured person, they should also give a conscious victim a COVID-19 screening questionnaire. In the case of even 1 positive response or if the injured person is not conscious, rescuers who approach the victim should wear adequate personal protective equipment (PPE), including particulate respirators (eg, FFP2, FFP3, or equivalent standard), 2 pairs of disposable gloves, goggles, and coverall suit. A rescue operator wearing PPE is shown in Figure 2. The sequence for putting on and removing PPE is shown in Figure 3. The environmental scenario and risk-benefit ratio should be considered regarding wearing of coverall suits because they can dramatically worsen working conditions during rescue operations, such as in high heat-stress situations or in complex technical operations. At the end of the operation, the vehicle and nondisposable PPE used for the rescue should be disinfected with sodium hypochlorite

\section{DONNING PPE}

1. HAND ANTISEPSIS WITH HYDROALCOHOLIC GEL

2. WEAR A FIRST PAIR OF DISPOSABLE GLOVES

3. WEAR COVERALL SUIT (without wearing hood)

4. WEAR PARTICULATE RESPIRATOR (FFP2 OR FFP3)

5. WEAR COVERALL SUIT HOOD

6. WEAR GOOGLES

7. WEAR SECOND PAIR OF DISPOSABLE GLOVES

8. WEAR WORK GLOVES

9. WEAR PROTECTIVE HELMET

10. WEAR CLIMBING HARNESS OVER THE COVERALL SUIT

11. CHECK THAT ALL PPE HAVE BEEN WORN CORRECTLY

\section{DOFFING PPE}

1. ARRANGE 2 PLASTIC BAGS (one for the disposable PPE and one for non-disposable PPE)

2. REMOVE WORK GLOVES (non- disposable PPE bag)

3. REMOVE SECOND PAIR OF DISPOSABLE GLOVES

4. REMOVE PROTECTIVE HELMET (non- disposable PPE bag)

5. REMOVE GOOGLES

6. REMOVE RACING HARNESS (non- disposable PPE bag)

7. REMOVE HOOD AND COVERALL SUIT: while removing the coverall suit, fold or roll it upside down in a bundle

8. REMOVE BOOTS (non-disposable PPE bag)

9. HAND ANTISEPSIS WITH HYDROALCOHOLIC GEL

10. REMOVE PARTICULATE RESPIRATOR without touching the mask front-side

11. REMOVE THE FIRST PAIR OF DISPOSABLE GLOVES

12. HAND ANTISEPSIS WITH HYDROALCOHOLIC GEL

13. TAKE A SHOWER AS SOON AS POSSIBLE

Figure 3. Putting on and removing personal protective equipment.

$(0.1-0.5 \%), 70 \%$ ethanol, or hydrogen peroxide solution (3\%) by operators wearing adequate PPE. ${ }^{7}$

Given that mountaineering has become increasingly popular since the 19th century and that the number of accidents has correspondingly increased, ${ }^{8}$ this novel outbreak could challenge rescue operators worldwide.

In conclusion, during the COVID-19 pandemic, protocols for mountain rescue services should be reassessed to protect both rescuers and victims from possible contagion. Cross-infection among rescue operators should also be considered and prevented by applying adequate precautions and physical distancing.

Domenico Massullo, MD

Anesthesia and Intensive Care Medicine Department of Clinical and Surgical Translational Medicine Sapienza University of Rome Rome, Italy; 
National Medical School of Italian Alpine Rescue Corps

CNSAS

Milan, Italy

Silvia Fiorelli, MD

Anesthesia and Intensive Care Medicine

Department of Clinical and Surgical Translational

Medicine

Sapienza University of Rome

Rome, Italy

Patrizio Rubcich, MD

Anesthesia and Intensive Care Medicine

Department of Clinical and Surgical Translational

Medicine

Sapienza University of Rome

Rome, Italy;

National Medical School of Italian Alpine Rescue Corps

CNSAS

Milan, Italy

Domenico Romano, DNP

Gianluca Facchetti, MD

National Medical School of Italian Alpine Rescue Corps

CNSAS

Milan, Italy

\section{References}

1. Huang C, Wang Y, Li X, Ren L, Zhao J, Hu Y, et al. Clinical features of patients infected with 2019 novel coronavirus in Wuhan, China. Lancet. 2020;395(10223): 497-506.

2. The species severe acute respiratory syndrome-related coronavirus: classifying 2019-nCoV and naming it SARS-CoV2. Nat Microbiol. 2020;5(4):536-44.

3. Wu Z, McGoogan JM. Characteristics of and important lessons from the coronavirus disease 2019 (COVID-19) outbreak in China: summary of a report of 72,314 cases from the Chinese Center for Disease Control and Prevention. JAMA. 2020;323(13):1239-42.

4. Li Q, Guan X, Wu P, Wang X, Zhou L, Tong Y, et al. Early transmission dynamics in Wuhan, China, of novel coronavirus-infected pneumonia. $N$ Engl $J$ Med. 2020;382(13):1199-207.

5. Chen R, People S. Expert consensus on preventing nosocomial transmission during respiratory care for critically ill patients infected by 2019 novel coronavirus pneumonia. Zhonghua Jie He He Hu Xi Za Zhi. 2020;20(17):1-21.

6. Long QX, Liu BZ, Deng HJ, Wu GC, Deng K, Chen YK, et al. Antibody responses to SARS-CoV-2 in patients with COVID-19. Nat Med. 2020;26(6):845-8.

7. Fathizadeh H, Maroufi P, Momen-Heravi M, Dao S, Köse S, Ganbarov K, et al. Protection and disinfection policies against SARS-CoV-2 (COVID-19). Infez, Med. 2020;28(2): 185-91.
8. Donelan S. Mountaineering and mountain rescue-an introduction. Wilderness Environ Med. 2004;15(1):42-3.

\section{Sudden Death Following Hump-Nosed Pit Viper (Hypnale hypnale) Bite}

\section{To the Editor:}

Hump-nosed vipers of the genus Hypnale are venomous pit vipers endemic to Sri Lanka and southwestern India. They are the most common cause of venomous snakebites in Sri Lanka, causing 27 to $77 \%$ of all snakebites. ${ }^{1}$ Usually, their bites cause local envenoming only. ${ }^{2}$ Less frequently, bites can cause significant morbidities, such as acute kidney injury, chronic kidney disease, ${ }^{3}$ venom-induced consumption coagulopathy, ${ }^{4}$ chronic wounds, and amputations of digits. ${ }^{2}$ Death after hump-nosed viper bites is very rare, and the mortality rate is about 0.9 to $1 \%$. $^{2,5}$ When death does occur, it is usually in the days after the bite. To our knowledge, sudden death has not been previously reported after a hump-nosed viper bite. We report a fatal case of proven $H$ hypnale bite in which the victim died approximately 45 min after the bite.

A 60-y-old male, diabetic estate worker was bitten by a hump-nosed viper while he was working on property situated about $5 \mathrm{~km}$ away from his house. He lived in Nivithigala, a remote village in the Ratnapura district, and had gone to the estate in his own 3-wheeled vehicle at around 1000. The snakebite occurred on the left dorsum of his foot at around 1030. He killed the snake, came back home by his vehicle at around 1045, told the story to his wife, and identified the snake as a Polon thelissa (the Sinhala name for hump-nosed pit viper). He and his wife planned to go to a nearby local hospital situated about $8 \mathrm{~km}$ from their house. At that time, he had mild pain at the site of bite and few drops of bleeding. While he was changing his shirt, he collapsed and noted pain in his left arm. He was carried to the local hospital at about 1115 . He did not speak on the way to the hospital, and upon arrival, he was declared dead by the admitting medical officer. The snake, which was brought to the local hospital, was identified as a hump-nosed viper by the admitting medical officer. The man's body was transferred to Teaching Hospital Ratnapura for postmortem examination, along with the offending snake. According to the standard key, ${ }^{6}$ the snake was identified as $H$ hypnale (Figure 1) by the corresponding author. Autopsy examination showed pulmonary and myocardial hemorrhage. Kidneys, liver, brain, and coronary vessels were macroscopically normal. Acute renal tubular necrosis, acute ischemic damage to the brain, and pulmonary hemorrhage were observed on microscopic examination (Figure 2). 